\title{
OBITUARY
}

\section{DR. PETER MCBRIDE}

THE recent death of Dr. Peter McBride at the age of 92 has severed the last remaining living link with the early days of laryngology in Edinburgh. Born in Hamburg, Peter McBride was educated at Clifton College and Edinburgh University. After qualifying M.B. in 1876 he served as House Physician in the Royal Infirmary and became M.D. in I88I. He was elected a Fellow of the Royal College of Physicians in I88o. Unlike otology, which was a surgical speciality from the first, laryngology was a child of medicine and the laryngologist was a physician.

McBride amplified his studies in Vienna, then the medical post-graduate teaching centre of the world and on his return to Edinburgh he was appointed Surgeon to the Eye, Ear and Throat Infirmary in Cambridge Street and Lecturer on Diseases of the Ear, Nose and Throat in the extramural school of the Royal Colleges. Otology and laryngology were studied and practised as separate subjects in London, Glasgow and elsewhere, but in Edinburgh they were united from the first.

In 1883 a department consisting of one small room in which patients were seen twice a week was allotted to the speciality in the Royal Infirmary, and in 1897 the University established a lectureship on diseases of the Ear, Nose and Throat. Dr. McBride was the first to hold each of those appointments, and it was largely owing to his hard work and initiative that a fully equipped department was established before his retirement in I903. His writing was clear and concise and it is not surprising that his text book, Diseases of the Throat, Nose and Ear, originally published in I89I retained its popularity through three editions. In the preface to that work, one may find a statement which reveals the logical mind of the writer: "All drawings of instruments have been omitted ... They are unnecessary for the simple reason that the practitioner must possess the means of operating before he proceeds to operate".

Dr. McBride's ability won for him many honours; in 1883 he became a Fellow of the Royal Society of Edinburgh, he was President of the Laryngological Society of London, of the Otological Section of the Royal Society of Medicine, and of the Section of Otology and Laryngology at the British Medical Association Meetings; he was also elected an Honnrary Member of the Scottish Otological and Laryngological Society. In I9I3 he delivered the Semon lecture at the University of London. On retiring from practice in Igro he went to live in Yorkshire, at first at Harrogate and latterly at York. There, so long as health and energy permitted, he indulged his favourite sport of hunting. Throughout his life he took a keen interest in all sports and games. His years of retirement were also employed in 


\section{Obituary}

writing interesting contributions to philosophy and psychology. Perhaps the most popular of those works are his essay entitled Psycho-analysis Analysed (I924) and his later Philosophy of Sport (I932).

Peter McBride was a charming companion and it was a great pleasure for old friends to renew acquaintance with him during his frequent visits to Edinburgh after his retirement. It was characteristic of him that during the war of IgI4-Igr 8 he returned to voluntary work as laryngologist at the 2nd Scottish General Hospital under Dr. Logan Turner who had formerly been his assistant. Endowed with a rich fund of humour, he was an excellent raconteur. At the close of his long and useful life we honour the memory of this doughty pioneer of laryngology.

D.G. 